\title{
Axonal degeneration in multiple sclerosis: can we predict and prevent permanent disability?
}

\author{
Jae Young Lee ${ }^{1}$, Kasra Taghian ${ }^{2}$ and Steven Petratos ${ }^{*}$
}

\begin{abstract}
Axonal degeneration is a major determinant of permanent neurological impairment during multiple sclerosis (MS). Due to the variable course of clinical disease and the heterogeneity of MS lesions, the mechanisms governing axonal degeneration may differ between disease stages. While the etiology of MS remains elusive, there now exist potential prognostic biomarkers that can predict the conversion to clinically definite MS. Specialized imaging techniques identifying axonal injury and drop-out are becoming established in clinical practice as a predictive measure of MS progression, such as optical coherence tomography (OCT) or diffusion tensor imaging (DTI). However, these imaging techniques are still being debated as predictive biomarkers since controversy surrounds their lesion-specific association with expanded disability status scale (EDSS). A more promising diagnostic measure of axonal degeneration has been argued for the detection of reduced N-acetyl aspartate (NAA) and Creatine ratios via magnetic resonance spectroscopic (MRS) imaging, but again fail with its specificity for predicting actual axonal degeneration. Greater accuracy of predictive biomarkers is therefore warranted and may include CSF neurofilament light chain (NF-L) and neurofilament heavy chain (NF-H) levels, for progressive MS. Furthermore, defining the molecular mechanisms that occur during the neurodegenerative changes in the various subgroups of MS may in fact prove vital for the future development of efficacious neuroprotective therapies. The clinical translation of a combined $\mathrm{Na}^{+}$and $\mathrm{Ca}^{2+}$ channel blocker may lead to the establishment of a bona fide neuroprotective agent for the treatment of progressive MS. However, more specific therapeutic targets to limit axonal damage in MS need investigation and may include such integral axonal proteins such as the collapsin response mediator protein-2 (CRMP-2), a molecule which upon post-translational modification may propagate axonal degeneration in MS. In this review, we discuss the current clinical determinants of axonal damage in MS and consider the cellular and molecular mechanisms that may initiate these neurodegenerative changes. In particular we highlight the therapeutic candidates that may formulate novel therapeutic strategies to limit axonal degeneration and EDSS during progressive MS.
\end{abstract}

Keywords: Axonal degeneration, Multiple sclerosis, Biomarkers, NF-L, N-Acetyl aspartate (NAA)/Creatine ratio, Microglia, Sodium channels, Collapsin response mediator protein 2, Calpain

\section{Introduction}

Destructive, inflammatory demyelinating multiple sclerosis (MS) lesions can occur throughout the central nervous system (CNS) with preferential anatomical patterns forming. Clinical symptoms in an MS patient may manifest as a range of neurological deficits, including paresthesia, dysesthesia, weakness, or visual disturbances such as blurring or greying of vision and black spots in the visual field (scotoma, a consequence of optic neuritis). There have

\footnotetext{
* Correspondence: steven.petratos@monash.edu

'Department of Medicine, Central Clinical School, Monash University, Prahran, Victoria 3004, Australia

Full list of author information is available at the end of the article
}

been several risk factors postulated for the development of MS, namely genetic, inadequate exposure to Vitamin D, smoking, Epstein Barr virus infection early in life and geographical in relation to latitude gradient [1]. In approximately $90 \%$ of cases, the disease manifests with an initial primary phase characterized by a relapsing-remitting presentation (RRMS) where the patient experiences alternating episodes of neurological impairment, followed by recovery [2]. The secondary phase involves the transformation of a relapsing-remitting presentation into a secondary progressive MS (SPMS), which involves a persistent neurological decline [2]. In contrast, $10 \%$ of patients undergo primary progressive MS (PPMS) where the course of the disease 
adopts a steady decline in neurological function without any periods of recovery [2]. The prognosis of MS can also vary from complete and lasting remission to eventual paralysis, loss of bowel and bladder control and blindness [3], and even death in the case of the most aggressive form of the disease, acute rapid progressive MS [3].

Therefore, MS is considered a heterogeneous condition where disease features may vary from one patient to another. Despite the different histopathologically characterized lesions of MS, they share common hallmarks that include areas of focal demyelination with inflammatory infiltrating immune cells, along with axonal injury. Contrary to the original focus of research on the autoimmune mechanisms that are operative in MS, there is now clear evidence that axonal damage/loss is the major determinant of profound neurological deficit in MS sufferers. In light of the variable course of the disease and different prognostic outcomes we discuss the possibility that in some subgroups of MS, molecular mechanisms may initiate axonal degeneration as a primary event, preceding inflammatory destruction of myelin, leading to variable capacity for repair and thus variable patient presentation.

This review focuses primarily on why MS may progress to permanent disability. The discussion covers clinical, pathological, cellular and molecular mechanisms, which govern axonal pathology in progressive MS, the etiology of permanent neurological disability. The recent advances in biomarkers and possible molecular mechanisms driving axonal dysfunction through ion channel and axonal transport defects will be highlighted with an emphasis on therapeutic targeting in an attempt to halt axonal pathology and hence progression of the disease.

\section{Axonal indicators in the neurology clinic}

Currently there is no clinical, laboratory, imaging or pathological sign of MS that is pathognomonic for the disease. At present, the diagnosis of MS is based on the two McDonald criteria [3]. The first being that there should be evidence of at least two demyelinating lesions in the CNS that are separated both spatially and temporally. The second criterion is that all other alternative diagnoses are ruled out by clinical investigation. Therefore, the diagnosis of MS essentially remains one of exclusion from the clinical evidence provided and so the need for diagnostic biomarkers is warranted in particular to personalize therapeutic regimes.

Defining axonal damage during MS, a prediction of progression, has proven somewhat problematic since conventional magnetic resonance imaging (MRI) does not provide clinicians with an accurate interpretation of the underlying pathology. Despite numerous biomarkers of axonal damage being recently reported to be superior in their diagnostic and eventual prognostic capacities for
MS progression, limitations still exist for their utility in isolation.

\section{Current imaging techniques}

Further revision of the McDonald criteria in 2010 has led to a more simplified version of MS diagnosis which now include those patients that present with CIS, either as monofocal or multifocal demyelinating lesions, with involvement of the optic nerve, brainstem and cerebellum, spinal cord and cerebral deep white matter tracts [4]. Such slow expanding lesions on progression, can be absent by T1-weighted MRI inspection following gadolinium (Gd) enhancement [2].

Current MRI technologies are elucidating the substantial involvement of axonal degeneration with increasing disability parameters [5], previously difficult to define. High resolution diffusion tensor imaging (DTI) has been used in a rat model of experimental autoimmune encephalomyelitis (EAE), generating data which support the contention that significant axonal damage and loss can occur at some distance from the primary inflammatory lesion, strongly correlating with disability [6]. Alterations in DTI measurements are also well documented in MS patients [7]. Two main parameters that are disturbed in MS patients are mean diffusivity (a quantitative metric of water diffusion) and fractional anisotropy (prevalence of diffusivity along one direction) [8]. Increase in mean diffusivity often reflects edema, axonal and myelin loss [9] whereas reduction in fractional anisotropy indicates demyelination in MS [10]. Increased mean diffusivity and decreased fractional anisotropy were detected in NAWM of MS patients [11]. These changes were more profound in SPMS patients compared with CIS, RRMS and benign MS [12]. Moreover, these diffusion abnormalities were also found in grey matter of MS patients where axonal or neurodegeneration are prominent, shown to be greater in SPMS compared with other MS phenotypes [12]. Attempts have been made to correlate diffusion alteration to EDSS, however, the results of these studies remain controversial [13-19]. Since EDSS is based on motor system criteria, it can be suggested that motor-system specific DTI measurement would have a high correlation with EDSS. In fact, region-specific DTI measurements in MS patients have indicated a greater correlation of DTI changes in motor tracts with EDSS [20]. Importantly, it has been recently proposed that a reduction in axial diffusivity measurements of DTI correlate to extensive neuroinflammatorymediated axonal damage within the optic nerve following acute optic neuritis, often a primary indicator of MS [21]. Moreover, these investigators demonstrated that protracted reduction in axial diffusivity measurements correlated with pronounced retinal nerve fiber layer (RNFL) thinning and multifocal visual evoked potential 
(mfVEP) amplitude loss at 12 months. Therefore, the argument for the use of axial diffusivity measures as a predictor of poorer visual outcomes in patients is justified and may in fact be an excellent biomarker for neuroprotective therapies in MS that limit axonal degeneration.

Another non-conventional MRI approach utilized to study axonal degeneration is the magnetization transfer ratio, which has been demonstrated to show strong correlations with the degree of myelin content, therefore serving as an indicator of axonal degeneration [22]. Recently, accurate imaging of axonal degeneration in vivo has been established through optical coherence tomography (OCT), which measures the thickness of the RNFL [23]. It has been well established that Wallerian degeneration along retinal ganglion cell axonal fibers inevitably reaches the RNFL, which is unmyelinated and so axonal degeneration alone can be measured [24]. Given that optic neuritis is a prevalent initial clinical finding in MS, Klistorner et al., [24] have focused the clinical assessment of the disease by imaging the optic nerve. These investigators have shown a direct correlation between decreased amplitude and increased latency (markers of demyelination), measured with the newly developed mfVEP and the reduction in RNFL thickness (markers of axonal degeneration/loss). By performing these measurements on patients either suspected to have MS or those newly diagnosed post-acute optic neuritis, these investigators showed that axonal degeneration/loss was a prevalent finding in the context of neuroinflammation and demyelination [24]. A very recent study by these investigators has shown that the temporal RNFL is thinned in MS patients without previously presenting with optic neuritis and this was correlated with inflammatory lesions in the optic radiations, detected by DTI [25]. Such technology can provide high-resolution reconstruction of the retina (an anatomical site targeted during the early neurodegenerative process of MS). Therefore, OCT may be a plausible method to predict axonal degeneration and hence neurological impairment in MS patients with the added feature of studying the efficacy of neuroprotective therapies during the course of the disease. However, prospective multicenter studies have advocated for strict quality control criteria be implemented since boundary line errors due to poor scan quality and ring scan de-centration are common issues of clinical disagreement [26,27]. This has sparked the implementation of essential quality control criteria, identifiable as "OSCAR IB" (see [26]) and brought about debate of its clinical validity as an imaging biomarker purely on protocol and generation of artefacts. The clinical validity of OCT relies heavily on its inability to be the arbiter of CNS tissue injury and in particular since there still exist contradictory findings related to its ability in differentiating between the various subtypes of MS [27].
A means by which the degree of axonal degeneration may be studied involves the use of magnetic resonance spectroscopic (MRS) imaging. MRS allows for the detection of changes in metabolites such as $\mathrm{N}$-acetyl aspartate (NAA), a marker of axonal integrity [28]. Reduced levels of NAA can be interpreted as potentiated axonal damage during the course of neurological diseases that involve axonopathy [28]. Whole brain MRS has successfully shown significant reduction in NAA and NAA/Creatine (NAA/Cr) ratio in CIS and RRMS compared with normal healthy controls [29-31]. However, these changes were not correlated with EDSS, limiting the clinical utility of these data. Reduction in NAA and NAA/Cr ratio was found in normal appearing white matter (NAWM) of RRMS and SPMS and interestingly, these changes were correlated with EDSS [32-39]. Importantly, it was found that the reduction in NAA levels demonstrated within NAWM of frontal and parietal brain areas were more evident in progressive manifestations of MS than RRMS [39]. Furthermore, studies have demonstrated that the reduction in NAA levels was more significant in T1 hypointense Gd-unenhancing lesions than acute lesions and no significant relationship between T2 hyperintense lesions with NAA levels [35-38]. These studies reflect the clinical relevance in measuring altered NAA levels during the course of MS as a biomarker for axonal damage in NAWM and both acute and chronic inflammatory lesions.

However, the MRS signal obtained for NAA may not necessarily correlate with tissue atrophy and axonal damage per se. In fact measurements obtained from the corpus callosum of patients with CDMS, via the sensitive diffusion fractional anisotropy, could demonstrate reduced size which correlated with patient EDSS but no such correlation could be seen with reduced NAA levels relative to tissue water [40]. Furthermore, while the MRS analysis from the spinal cords of patients primarily with SPMS clearly demonstrated reduced NAA levels with excellent correlation to only moderate EDSS and tissue atrophy [41]. Despite these encouraging findings, no statistically significant reduction in NAA levels could be attributed to NAWM areas in the frontoparietal cortices of these patients. It is also worth noting that although a 12-month longitudinal study was performed to evaluate the neuroprotective efficacy of interferon beta therapy, no restoration in NAA/Cr ratio could be observed in RRMS patients despite a reduction in CNS inflammatory lesions and relapse rates [42]. It is also not uncommon for NAA levels to be restored in RRMS in the lesion core and NAWM $[43,44]$. A further confounding factor to the limitation of NAA levels as a measure of axonal integrity is that fact that it is more likely a marker of neuro-axonal energy dysfunction, with an abrogated electron transport chain resulting in the 
plummeting levels of NAA [45]. Therefore, outside the added technical issues of accurate measurement [46], its pathobiological relevance as a predictive biomarker is still in question partly due to the heterogeneity of patient cohorts and the limited multicenter assessments performed.

However, these imaging techniques have also been used to study cortical adaptive functions in patients with RRMS, SPMS and PPMS $[47,48]$. In the initial disease presentation (RRMS), there seems no (or slight) reduction in NAA levels, however, a prominent reduction in NAA levels can be captured during progressive MS [47,49]. In accordance with progressive MS, changes in NAA levels within cortical grey matter were correlated with EDSS, auditive selective attention and cognitive performance $[48,50,51]$. Overall, changes in NAA in both NAWM and cortical grey matter can be strongly linked with physical disability. Indeed, a longitudinal therapeutic study of glatiramer acetate (FDA-approved disease modifying drug, Copaxone) treatment for RRMS, demonstrated partial recovery of NAA/Cr ratio [52]. Furthermore, an amalgamation of DTI and MRS using a 7 tesla magnet allowed for a more sensitive measurement of axonal damage within NAWM regions of the corpus callosum, demonstrating a clear reduction of NAA/Cr ratio, thereby supporting NAA reduction as a biomarker for to axonopathy during the course of MS [53].

As axonal degeneration can directly correlate with disease progression, a reliable prognostic biomarker for MS must target the detection of clear, reproducible axonal changes. Even though demyelination is a pathognomic feature of MS, a recent study has identified patients that exhibit a normal baseline MRI but present clinically with optic neuritis, have eventually manifested CDMS [54]. Demyelinating lesions, as detected through imaging techniques, cannot be a reliable diagnostic tool for MS. Although the levels of NF-H in the CSF, along with MRS measurement of NAA, are promising biomarkers of axonal damage during the clinical progression of MS, a combination of MRI (to detect demyelinating lesions) and MRS (detection of axonal changes) can be a powerful diagnostic and prognostic tool for nascent MS findings and progressive disease.

\section{Molecular biomarkers: we are not there yet}

Detecting the presence of neuron-specific proteins in the CSF can be a powerful diagnostic/prognostic tool during MS, only if these proteins are shown to be directly correlative to the pathological sequelae of progression, beyond a causal association. Although lumbar puncture is considered as a safe method of obtaining CSF samples, its invasive nature, with requisite continuous sampling, is a limitation for the development of potential prognostic biomarkers of its incorporation in any clinical research study [55]. Despite this limitation, studies that have implemented
CSF collection from patients during the progression of their MS have uncovered elevated levels of NF-L, a potential biomarker for axonal damage and a possible prognostic measure of progressive MS (Figure 1) [56]. The major drawback of these studies is the disparity in findings amongst specific patient groups with variable neurological presentations and tissue injury, bringing in to question the reproducibility of CSF NF-L levels as phenotypic biomarker.

As neurofilament is an integral protein that forms the axonal cytoskeleton, detection of neurofilament and its breakdown peptides within the CSF or serum can predict definitive axonal damage in situ. For instance, elevated levels of NF-L have been detected in CSF samples from individuals presenting with CIS which have subsequently progressed to CDMS [57]. More specifically in CIS, NF-L levels were increased when compared with control CSF samples obtained from patients with neuropsychiatric diseases of non-inflammatory etiology [58]. These elevated NF-L levels in the CSF were observed to be even greater in progressive MS or during relapse than those present in stable RRMS [59,60]. Circulating NF-L antigens in the CSF have also been postulated to trigger further autoimmunity against axons [61,62], experimentally illustrated through the immunization of mice with NF-L, which developed a progressive form of MS (predominant axonal damage with increased grey matter pathology) (Figure 1) [61,62].

The other major isoform, neurofilament heavy chain (NF-H), has also been found to be elevated in the CSF of all clinical MS types compared with normal healthy controls [63]. In particular, elevated levels have been reported in CIS with direct comparisons to neuropsychiartric diseases of non-inflammatory etiology [58], and these changes were correlated with declining EDSS [63]. These results emphasize that the level of NF-H in the CSF may relate to clinical disability. In comparison to NF-L, change in the CSF level of NF-H would appear to be more prominent in progressive MS [56]. However, again the major problem here is the confounding variable nature of the immunoassay results detecting NF-H levels observed from varying patient groups and different laboratories, rendering the data as possibly spurious [56].

It has recently been demonstrated that the immunotherapeutic, natalizumab, was shown to limit the rise in NF-L CSF levels during relapsing MS [64-66]. In addition, serum NF-H levels were shown to decrease during SPMS, when patients were treated with $\mathrm{Na}^{+}$channel blocker, lamotrigine (based on serum lamotrigine adherence) [67]. The serum levels of NF-H were shown to correlate with clinical disability, EDSS and MRI cerebral atrophy [67] which further supports the notion that serum NF-H levels can manifest during disease progression and more likely in chronic MS (Figure 1). The possibilities of these 


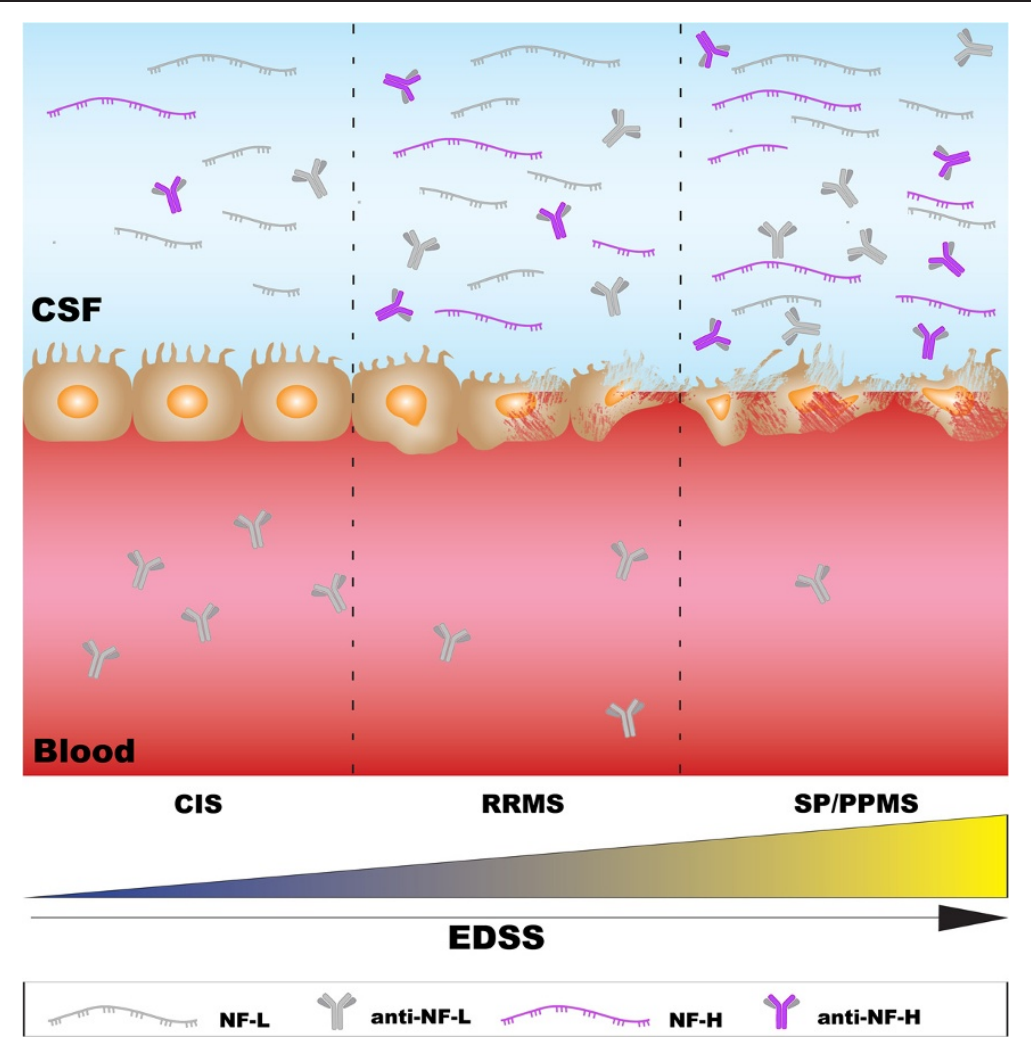

Figure 1 Sequestered neurofilament and anti-neurofilament as potential prognostic biomarkers for progressive MS. Both NF-L and NF-H can be released from CNS parenchymal cells into the CSF during clinical course of MS. The CSF levels of NF-L are consistently high throughout the disease progression, whereas the CSF levels of NF-H increase upon disease progression. Free NF-L and NF-H can be recognized by dendritic cells (antigen presenting cells) culminating in a further cycle of inflammation. These cells can therefore, activate B cells and T helper ( $T_{H}$ ) cells. Activated B cells can release autoantibodies against both NF-L and NF-H, which can potentiate axonal damage. The CSF levels of anti-NF-L and anti-NF-H increase during progressive MS, whereas the serum levels of anti-NF-L may decrease.

clinically relevant studies are that both the NF-L and NF$\mathrm{H}$ levels are stable molecules with excellent predictive nature of clinical outcome with regard to progression and quite possibly ongoing axonal damage following disease modifying therapeutic interventions. Despite this enthusiasm, MS patients on natalizumab still progress and the cerebral volume measurements in the lamotrigine trial did not advocate for neuroprotection, suggesting that we still await definitive evidence that NF-L and/or NF-H are clinically relevant biomarkers of axonal damage and predictive of MS progression.

Mechanisms of axonal injury and degeneration during MS Energy-dependent mechanisms of axonal degeneration

Following demyelination, the substantial energy demands placed upon axons, increase the stationary size of mitochondria and the speed of their transport along axonal microtubules [68]. Recent live in vivo imaging techniques applied in $\mathrm{MOG}_{35-55}$-EAE-induced mice revealed functional defects in intra-axonal mitochondria occurring even before prominent demyelination. This suggests that axonal mitochondria may be undergoing substantial damage prior to demyelination, indicating that an energy imbalance in axons may be the driver of the axo-glial degenerative phase. Recently, comprehensive reviews have covered the experiments that outline the unique mitochondrial deficits along with the generation of reactive oxygen species (ROS) and reactive nitrogen species (RNS) during the disease course of EAE leading to compromised axonal integrity $[69,70]$ and so will not be discussed here.

Of particular importance to cortical atrophy attributed to MS pathology, whole-genome microarray analysis performed on post-mortem motor cortex tissue obtained from individuals who had exhibited SPMS, have demonstrated the down-regulation of neuronal-specific mitochondrial and cox genes, which encode for functional mitochondrial complex I and III activity [71]. In accordance with this finding, cortical chronic-active grey matter lesions also exhibited decreased complex IV activity along with multiple deletions of mitochondrial DNA [72]. On the other hand, in chronic-inactive lesions, increased complex IV activity was found [73], collectively indicating that there may be compensatory mechanisms during oxidative damage in cortical neurons [74]. This is 
in keeping with the increased mitochondrial density and complex IV activity observed in remyelinated axons from MS shadow plaques and in an ethidium bromide model of demyelination/remyelination [75] when compared with normally myelinated axons [75]. What this study highlights is that demyelination may cause delayed action potential propagation, possibly increasing axonal energy demand. However, when this energy demand exceeds axonal ATP production, it may undergo hypoxic-like axonal degeneration. Response to this state of hypoxia in axons may manifest as mitochondrial dysfunction due to an increase in NADPH oxidase or iNOS [2].

Dysregulation of mitochondrial transport can also severely impact the energy balance in axons, which may drive axonal degeneration. One scenario by which axonal degeneration may be initiated through mitochondrial dysfunction can be derived from the alterations exhibited in the histone deacetylases (HDACs). For the past decade, many groups have reported that HDAC inhibition was neuroprotective in MS (for review, see [76]). It was demonstrated that intraperitoneal administration of trichostatin A, a global inhibitor of HDACs, during $\mathrm{MOG}_{35-55}$-induced EAE could reduce disease severity. Furthermore, immunohistochemical analysis revealed that a higher axonal density in lumbo-sacral spinal cords could be demonstrated only in the trichostatin A treated group [77]. The molecular mechanism behind HDAC-mediated axonal degeneration was partially revealed by Kim et al., [78] who suggested that cuprizone-induced axonal damage can be triggered by $\mathrm{Ca}^{2+}$-dependent export of class I HDAC1 to the neuronal cytosol. This caused binding of HDAC1 with $\alpha-$ tubulin and kinesin motor proteins (KIF2A and KIF5), which were only detected in demyelinated areas, leading to an impairment of mitochondrial transport in neurons [78]. The same group also demonstrated a co-localization of cytosolic HDAC1 and SMI-32 in axons within demyelinated white matter, observed in human MS brain tissue [78]. As HDAC recruitment was found to be essential during remyelination upon lysolecithin-induced demyelination [79], the molecular mechanisms underlying HDAC inhibition mediated neuroprotection during neuroinflammation must be thoroughly characterized prior to clinical translation since they may target the myelin repair process.

Sirtuins (SIRT), class III family members of HDAC, have been raised as one of the candidate molecules that may serve as a therapeutic target to treat axonal degeneration in MS. Intravitreal administration of SIRT1 activator, SRT647 and SRT501, was shown to ameliorate retinal ganglion cell loss in $\mathrm{PLP}_{139-151}$-induced EAE within the SJL/J mouse model [80]. The same group also administered an oral dose of resveratrol, another SIRT1 activator and demonstrated neuroprotection in the same EAE model. Normal retrograde vesicular transport within retinal ganglion cell axons in mice treated with resveratrol was confirmed by fluorogold uptake assay and there was no modulation of neuroinflammatory or remyelination mechanisms upon resveratrol treatment [81]. Further investigation of the mechanism responsible for axonal integrity suggested that the neuroprotection exhibited by resveratrol in retinal ganglion cells during neuroinflammation may have been derived through the attenuation of oxidative stress by increasing the expression of the mitochondrial enzyme, succinate dehydrogenase and promoting deacetylation of the peroxisome proliferator activated receptor co-activator $1-\alpha$ (PGC-1 $\alpha)$ [82]. Overexpression of human SIRT1 in neurons of MOG $_{35-55}$-induced EAE mice demonstrated neuroprotection with reduced inflammation and demyelination. Increase in brain-derived growth factor (BDNF) was seen in SIRT1 overexpressed neurons, which may indicate that SIRT1 overexpression can restore BDNF function, subsequently facilitating axonal protection [83]. Although SIRT1 activation or overexpression in neurons can be neuroprotective during neuroinflammation, possible effects of SIRT1 on other cell types during demyelination or neuroinflammation must be vigilantly investigated.

A plausible reason to investigate other neural lineages may be as a result of the recent study by Rafalski et al., [84] which implied that SIRT1 inactivation specifically in neural stem cells, shown using a nestin-Cre/loxPsirt1 transgenic model, can improve remyelination upon lysolecithin-induced experimental demyelination as well as during $\mathrm{MOG}_{35-55}$-induced EAE [84]. As plasma levels of SIRT1 were found to be increased in MS patients when compared with non-neurological disease controls, it is also postulated that soluble/circulating SIRT1 is an adaptive response during MS and it may play an important role in disease pathogenesis [85]. Therefore, a more comprehensive understanding of the molecular mechanism governing axonal preservation achieved through the activity of SIRT1 must be achieved to classify it as a neuroprotective agent of therapeutic potential.

\section{Current ion channel theory in axonal damage}

The clinical use of sodium channel blockers to treat specific MS symptoms such as carbamazepine (the initial class of blockers) has fuelled interest in the mechanism by which persistent sodium influx can induce axonal injury during the symptomatic phase of MS. It has been posited that periods of remission from MS symptoms, may in-part, be related to a restoration of action potential conduction by $\mathrm{Na}^{+}$channels along denuded axons [86]. Despite a lack of electrophysiological data to support this hypothesis, following demyelination, denuded axons can increase their density and number of $\mathrm{Na}^{+}$ channels in MS lesions [87]. Increased numbers of $\mathrm{Na}^{+}$ channels in demyelinated axons may produce an increase 
in axonal membrane potential oscillations [88], thereby potentiating neurotoxic levels of intra-axonal $\mathrm{Ca}^{2+}$, culminating in axonal degeneration [89]. ROS and RNS have been known to exert damage to axonal mitochondria with the consequential diminished energy supply to the axon [74]. This energy failure involves the accumulation of large quantities of $\mathrm{Na}^{+}$within the axon due to the failed $\mathrm{Na}^{+}$ channels and persistent currents [90]. In response to this, the $\mathrm{Na}^{+}-\mathrm{Ca}^{2+}$ exchanger, which normally facilitates $\mathrm{Na}^{+}$ influx, instead functions in reverse mode to offset the rising levels of $\mathrm{Na}^{+}$within the axon. However, the elevation of intracellular $\mathrm{Ca}^{2+}$ levels, a consequence of the failure in the ion exchanger, leads to the activation of a common pathway precipitating axonal degeneration [90] (Figure 2). Despite this tantalising hypothesis, no direct experimental evidence exists for this ion channel mechanism to be operative during the progression of MS symptoms.
Over the past few years, Stephen Waxman and colleagues have led the field in identifying how $\mathrm{Na}^{+}$channels can initiate axonal degeneration in white matter tracts of the spinal cord of murine EAE models [91,92]. Notably, they have shown that the increased expression of $\mathrm{Na}_{\mathrm{v}} 1.6$ and $\mathrm{Na}^{+} / \mathrm{Ca}^{2+}$ exchanger is localized along damaged and demyelinated axons within many spinal cord tracts of EAE mice [89]. Mitochondrial dysfunction has been implicated in the reduction of axonal ATP levels, thereby rendering the $\mathrm{Na}^{+}, \mathrm{K}^{+}$-ATPase defective, compromising the ability for the axon to set up appropriate $\mathrm{Na}^{+}$transmembrane gradients and inevitably initiating the axonal degenerative process [93]. Blocking $\mathrm{Na}^{+}$ channels through the use of low dose TTX, phenytoin, lidocaine and flecainide, or blocking the $\mathrm{Na}^{+} / \mathrm{Ca}^{2+}$ exchanger through the use of bepridil has been successful in limiting the neurotoxicity after the induction of EAE

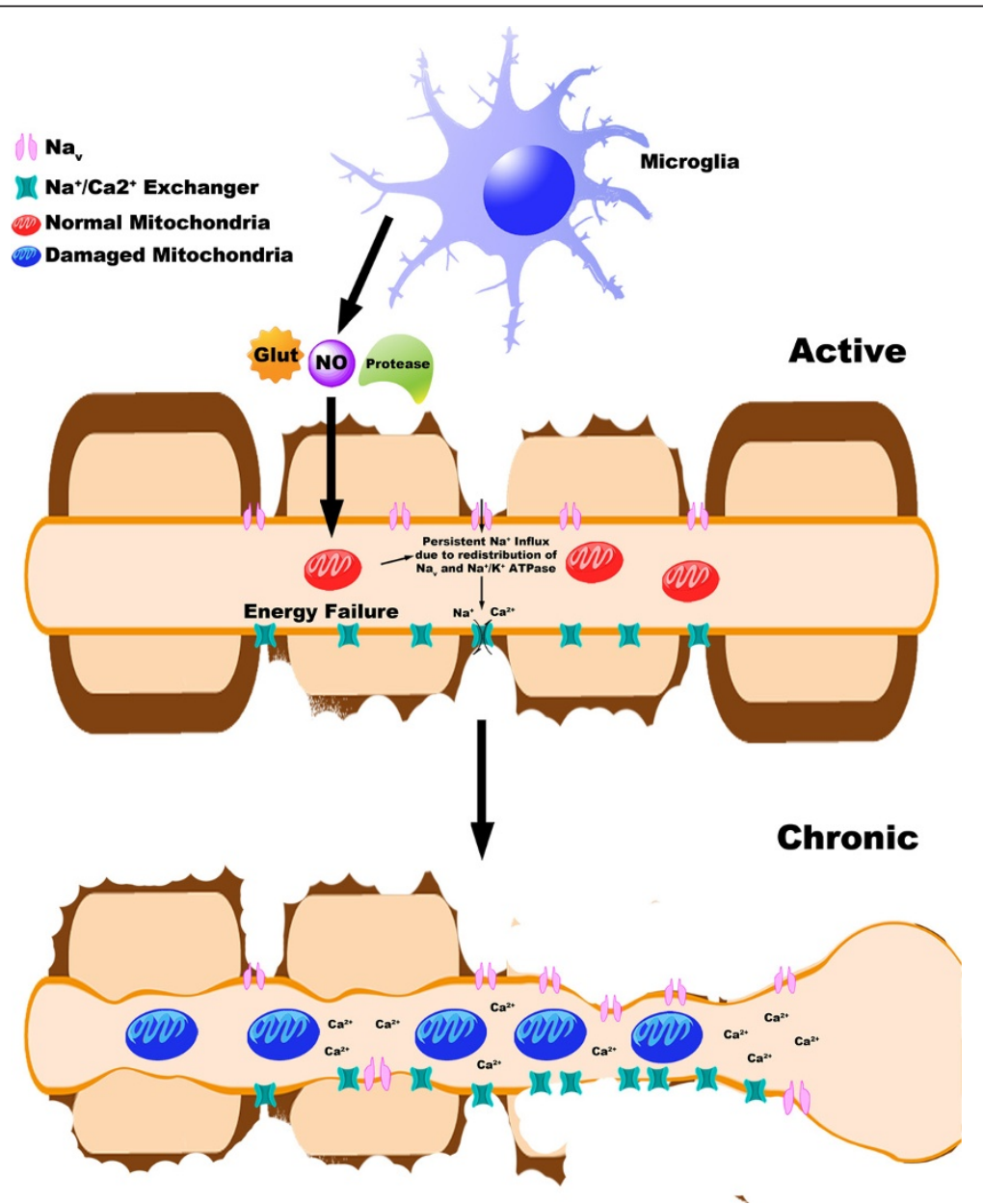

Figure 2 Activated microglia and the redistribution of ion channels can potentiate axonal injury during MS. Activated microglia can be a source of nitric oxide (NO), glutamate (Glut) or various proteases. Released free radicals, excitotoxic glutamate and various proteases can damage axonal mitochondria, leading to an imbalance in the energy demands/supply of axons. This along with the increased voltage-gated sodium channels $\left(\mathrm{Na}_{\mathrm{v}}\right)$ dispersed along denuded axons, can potentiate persistent $\mathrm{Na}^{+}$influx. To compensate for this redistribution, increased expression of the $\mathrm{Na}^{+} / \mathrm{Ca}^{2+}$ exchanger functions in reverse, thereby cytotoxic levels of $\mathrm{Ca}^{2+}$ can mediate axonopathy. 
[92,94-97]. These neuroprotective regimes tested in EAE suggest that one of the major mechanisms involved in axonal degeneration during neuroinflammatory diseases, is the persistent influx of $\mathrm{Na}^{+}$into the axon ultimately leading to neurotoxic levels of $\mathrm{Ca}^{2+}$ (for review see [86]). Not surprisingly, the therapeutic rationale for the treatment of neurodegenerative mechanisms associated with the acute and chronic sequelae of MS is gaining momentum, particularly since the outcome is to limit disability. Limiting axonal degeneration has the added benefit of possibly prohibiting the spread of further oligodendrocyte and myelin damage proximal and distal to the initial axonal lesion due to the maintenance of reciprocal growth factor-dependent mechanisms, with the potential for profound neurological benefit [2]. These mechanistic dissections of $\mathrm{Na}^{+}$channel blockers during neuroinflammatory disease have provided an evidence-based recruitment of patients in either PPMS, SPMS or RRMS for clinical phase trials in the US and the UK [98].

Another ion-channel blocking strategy set out to target Acid-sensing ion channel-1 (ASIC1), which is permeable to $\mathrm{Na}^{+}$and $\mathrm{Ca}^{2+}$ and can contribute to the excessive accumulation of intracellular ions. Both genetic knockout and pharmacological blockade of this ion channel was shown to be neuroprotective in EAE-induced mouse spinal cord tissue [99]. As this ion channel was upregulated in MS lesions, in particular degenerative axons overexpressing $\beta$ APP [100], these studies have thus lead to the clinical translation of amiloride (blocker of ASIC1), with the PPMS treatment group achieving neuroprotection, confirmed by DTI and MRI [101]. This approach is promising and it is now currently in a phase II clinical trial for optic neuritis in the UK (ClinicalTrials.gov identifier: NCT01802489). However, the data is preliminary with a very small patient group analysed and loose criteria set as biomarkers for axonal damage such as axial diffusivity and altered rates in brain atrophy measured in treated patients over time. Furthermore, the data did not exclude a reduction in inflammation as the primary mechanism of neuroprotection again without achieving discrimination whether the amelioration of injurious intracellular axonal levels of $\mathrm{Na}^{+}$and $\mathrm{Ca}^{2+}$ were the targets of amiloride treatment.

Although ion channel blockade holds substantial promise to limit axonal damage in MS, studies have reported significant worsening of disease upon withdrawal of specific ion channel blockers, a potentially fatal contraindication $[96,98]$. For example, it was demonstrated that administration of $\mathrm{Na}^{+}$channel blockers during EAE significantly reduce clinical EAE scores, however, upon withdrawal of these drugs, marked increase in clinical severity were observed which were associated with a burst of inflammatory infiltrates within the CNS [96]. This may be a result of the drug modulating the $\mathrm{Na}^{+}$channels immune cells, thereby exerting its neuroprotective effects via immunomodulation and not directly upon CNS axons as hypothesized. Furthermore, the Phase II clinical trial for lamotrigine $\left(\mathrm{Na}^{+}\right.$channel blocker), on secondary progressive MS patients showed exacerbation in motor function abnormalities, which were reverted upon a reduction in the lamotrigine dose [98]. These results clearly indicate the need for a sophisticated understanding of exact mechanism of action for such ion channel blockers. As other cell types do express ion channels, distinction of the modulatory effects of these partial blockers in immune cells and neurons would provide a more comprehensive understanding for their mechanisms of action. A very recent study by Al-Izki et al., [102] demonstrated a novel $\mathrm{Na}^{+}$ channel blocker (CFM6104) specifically targeted the early lesion (inflammatory penumbra) during EAE challenge in Biozzi $\mathrm{ABH}$ mice possibly through changes in p-glycoprotein [103], which was shown to be reduced both in EAE and MS lesions [102]. This novel drug reduced maximum severity of EAE disease score and improved motor-function during remission [102]. The authors have also found that there was no significant immunosuppression with this drug during EAE [102]. Although this study differentiated immunomodulation and neuroprotective drug actions, one should not overlook its possible rebound effects [96]. Furthermore, in the $\mathrm{MOG}_{35-55}$ EAE model a direct immunosuppressive role for the non-specific $\mathrm{Na}^{+}$channel blocker Phenytoin highlighted caution for its use in Clinical Trials as the specific cellular target remains clearly unresolved [96]. Therefore, thorough basic science studies are required to clearly distinguish the mechanisms of drug action and to identify possible side/rebound effects before its clinical translation.

\section{Cortical demyelination and atrophy - mechanisms governing progressive MS}

Retrograde neurodegeneration in demyelinating grey matter lesions within the corpus callosum and hippocampus during neuroinflammation has recently been shown in a marmoset model of EAE as indicated by increased immunostaining of $\beta \mathrm{APP}$ and decreased neuronal size and number [104]. Furthermore, increased SMI-34 (hyperphosphorylated NF-H) immunostaining was seen in demyelinating grey matter of the cerebral cortex of MS patients [105]. Attempts have been made to correlate these pathological changes with clinical disability (EDSS score), matching neuronal loss, axonal damage, and synaptic loss in demyelinating grey matter of hippocampus to memory loss [106-108]. Upon 12 weeks of cuprizonemediated experimental demyelination, epileptiform spikes were measured by EEG/video monitoring [109]. Further investigations revealed extensive demyelination and FluoroJade- $C$ immunostaining in the hippocampus of these 
animals with long-term treatment of cuprizone [109]. $\mathrm{MOG}_{35-55}$-induced EAE within a cohort of thy1-YFP reporter mice revealed that significant reductions in inhibitory neurons along with pre-synaptic puncta observed within demyelinating grey matter throughout the hippocampus may be the reason for the reduced spatial learning exhibited by these mice [110]. These animal experiments have led to clinicopathological investigations of cortical demyelination and ensuing neurodegeneration in MS patients. Significant neuronal loss and reduction in size of neuronal somata were reported to present within the chronic demyelinated hippocampal grey matter of progressive MS brain tissue [106]. Moreover, a microarray-based gene expression study of demyelinated hippocampi revealed that there was a significant decrease in genes that are involved in axonal transport [108]. A profound deficit in anterograde axonal transport has been postulated from data generated in this study which demonstrated reduced mRNA levels of the kinesin gene family; KIF1A, KIF3A, KIF15, KIF5B, KIF5C and kinectin (KTN1) in demyelinating hippocampi of MS patients [108]. Decreased immunostaining of KIF1A was also documented for these lesions and may suggest a reduced learning enhancement/plasticity associated with hippocampal degeneration/synaptic integrity [111]. In addition, a potential impairment of retrograde transport was reflected by the alteration of mRNA levels of dynein molecules; DYNC1L12, DCTN1 and DNAH17 [108]. These results strongly advocate for a correlation between cortical demyelination and neurodegeneration, potentially representing memory deficits in MS patients.

Concerning the mechanisms of cortical demyelination in MS, the literature provides several likely hypotheses. Bruce Trapp's group support the contention that alteration in glutamate uptake from hippocampal demyelination can cause neuronal energy imbalance thereby potentiating neurodegeneration [108]. A whole genome microarray approach revealed to these investigators that a decreased expression of glutamate receptors such as AMPA1, AMPA2 and AMPA3 in demyelinating hippocampi, may indicate an alteration of glutamate homeostasis [108]. Further bioinformatics analysis by the same group revealed that there were increased miR-124 levels, encoding for AMPA2 and AMPA3 in demyelinated hippocampi of MS patients. These changes could be reverted upon remyelination, hence, supporting the idea that myelin can influence glutamate homeostasis and demyelination can drive secondary neurodegeneration [112].

There exists evidence to suggest that the initiation of an autoimmune response can occur via the recognition of the glycoprotein autoantigen, contactin 2, on/near the endothelial cells of the grey matter by autoantibodies, type 1 helper T cells (Th1) and type 17 helper T cells (Th17) [113]. It is this process which enables the opening of the
$\mathrm{BBB}$, thereby allowing anti-myelin antibodies to gain access to the grey matter. Studies of PPMS have established a correlation between the degree of meningeal inflammation and cortical demyelination. This inflammatory state is believed to comprise increased concentrations of myelinotoxic and neurotoxic substances which in turn drive subpial pathology and demyelination, resulting in a greater disease severity [114]. Moreover, these investigators noted that monitoring brain atrophy over a 2-year period was an accurate prognostic indicator of disease progression. Further evidence of an immune response in the meninges as a pathophysiological mechanism of grey matter pathology is the presence of ectopic B cell follicle-like structures at these sites [115]. The extra-parenchymal structures are most commonly situated in the deep in-foldings of the cerebral sulci, and their numbers/extent are purported to be proportional to the size of cortical lesions present [116]. A large percentage of antigen experienced B cell clones present in the meningeal aggregates of $2 / 3$ of MS brains have also been observed to be present in the corresponding parenchymal infiltrates [117]. The follicles are comprised of aggregates of B cells, immunoglobulins (IgA and IgG) and IgM-positive plasma cells. Identified by immunohistochemical staining for proliferating B cells, these follicles vary in size and distribution throughout the brain [115]. The study by Magliozzi and colleagues reveal the cytotoxic effects that these B cell aggregates have on cortical tissue. Essentially the follicles contain CD8-positive T-cells expressing interferon-gamma (IFN- $\gamma$ ) which cause cortical pathology either directly by cytotoxicity or indirectly by the induction of microglial cell activation [118]. Furthermore, it is evident that the CD8-positive cells in these follicles have the capacity to cause greater damage than those in the grey matter itself [118]. In a very recent development an animal model mimicking meningeal inflammation and cortical demyelination has been achieved through the stereotactic injection of tumor necrosis factor (TNF) and IFN- $\gamma$ into the subarachnoid space following recombinant MOG immunization [119]. The data from this particular study implicates meningeal inflammation as a plausible initial pathology during neuroinflammation [119]. However, a relationship between meningeal inflammation and axonal pathology remains to be verified.

\section{Integral axonal proteins: the role of microtubule transport in MS/EAE}

Amyloid precursor protein ( $\beta \mathrm{APP})$ It is known that failure in axonal transport is one of the main causes of Wallerian degeneration [120]. Axonal transport deficits are often suggested to govern the pathologies which characterize classic neurodegenerative disorders, with Alzheimer's disease as the archetypal pathology with dystrophic axons from such catastrophic dysfunction of the molecular transport machinery [121]. The dysregulation of 
axonal vesicular transport within long myelinated fibers of the CNS in MS patients is a candidate mechanism for the induction of axonal degeneration possibly sharing this feature with other neurodegenerative conditions. The theory gathers momentum when one investigates a classical histopathological marker of axonal damage, the accumulation of $\beta A P P$, which is normally not detectable by immunostaining as it is transported fast enough along axons if their integrity is maintained. Immunohistochemical staining of $\beta$ APP however is intense in swollen axons of chronic-active MS lesions and is now widely accepted as marker for impaired axonal transport to demonstrate axonal damage in MS [122].

Collapsin response mediator proteins (CRMPs) CRMPs are a family of neuronal phosphoproteins [123] which regulate microtubule assembly as well as anterograde vesicular transport of important growth-related molecular cargo along neuronal microtubules [124,125]. CRMP2 (the most well defined of the CRMPs) has already been shown to be phosphorylated by Cdk-5 at Ser522 $[126,127]$, determined as the priming kinase, glycogen synthase kinase $3 \beta$ (GSK-3 $\beta$ ) at Thr514/509/Ser 518 $[128,129]$ and also Rho kinase at the Thr555 position $[130,131]$, all of which can mediate neurite retraction. Such phosphorylation disrupts the association of CRMP-2 with tubulin heterodimers so that tubulin is not able to be transported to the plus ends of microtubules for assembly, impeding directional growth of the neurite [125] (Figure 3). Importantly, phosphorylation of CRMP-2 reduces its binding to the kinesin-1 microtubule-related motor protein [132]. Since kinesin-1 is involved in anterograde vesicular axonal transport of molecules important for synaptic integrity and plasticity (e.g. BDNF receptor, TrkB) at the distal ends of axons [132], phosphorylation of CRMP-2 is expected to alter microtubule dynamics.

In terms of a pathogenic role attributed to the phosphorylated forms of CRMP-2, there is a clear link with the neurodegenerative processes of Alzheimer's disease (A $\beta$-mediated phosphorylated CRMP-2) [133,134]. Recently, our lab showed that a Rho kinase II- specific phosphorylated form of CRMP-2 has profound importance in EAE disease progression, where substantial increase in the degeneration of axons within the spinal cord and optic nerve could be observed. We found that the pThr555CRMP-2 form demonstrated during the peak stage of EAE can be reduced through the administration of a function blocking antibody against Nogo-A (potent neurite outgrowth inhibitor) or alternatively, through the overexpression of the phosphomutant form of CRMP-2 by using an adeno-associated virus serotype 2 gene delivery system, could individually reduce the markers of degenerative axons appearing [135]. Our laboratory is now specifically targeting the phosphorylation

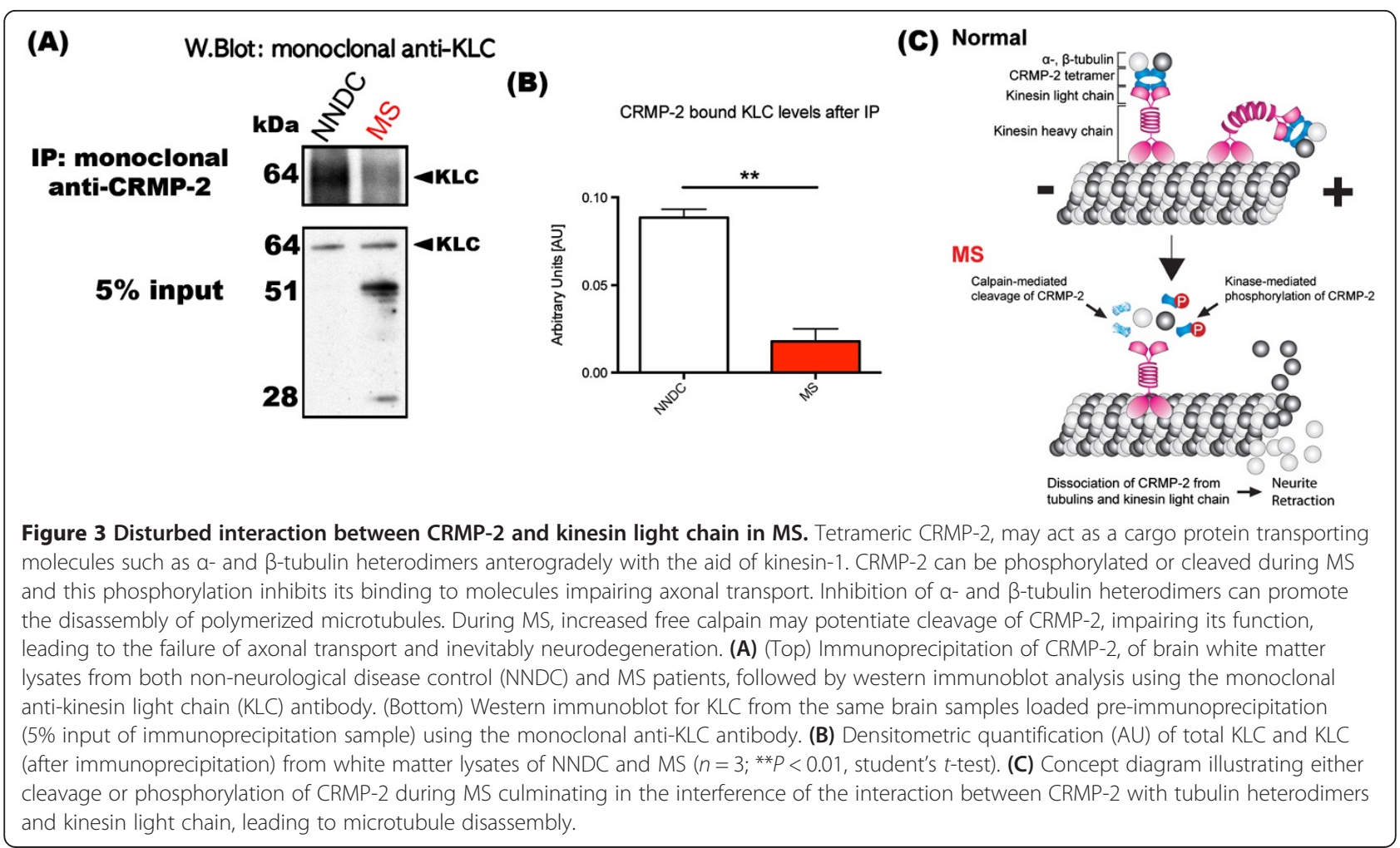


of CRMP-2, which may be a plausible therapeutic regime in the treatment of progressive MS.

\section{Calpains as de-stabilizers of the neuronal cytoskeleton in the MS model}

Calpain-mediated cleavage of integral myelin proteins, including myelin basic protein, has been proposed as a prominent pathological mechanism leading to profound demyelination during EAE disease onset and progression [136]. Indeed, translational expression and activity of calpain have been reported to increase in inflammatory cells, activated microglia and astrocytes at the time of onset of clinical signs during EAE $[137,138]$. More importantly, targeted calpain inhibition in the nervous system has been shown to reduce inflammation and demyelination in the CNS as well as the clinical signs of EAE [139], suggested to be the result of attenuating the peripheral immune response to the CNS [140].

Calpains are members of the highly conserved calciumdependent proteases capable of cleaving a vast array of cellular proteins [141]. Calpains are of specific interest in neurodegenerative disease since they can cleave cytoskeletal-related proteins such as the spectrin [142], tau [143], tubulin proteins and the CRMPs [144]. Since $\mathrm{Ca}^{2+}$-influx and the release of intracellular $\mathrm{Ca}^{2+}$ stores are plausible mechanisms by which axonal degeneration is potentiated during CNS injury and disease [141], the refractory transient increase in the deleterious calpains can potentially cause cleavage of cytoskeletal proteins and thus the collapse and degeneration of axons affected by these intracellular changes.

Two major isoforms of calpains exist namely, calpain-I ( $\mu$-calpain) activated at micromolar concentrations, and calpain-II (m-calpain) activated at up to millimolar concentrations [145]. In EAE, calpain is increased in axons due to the alteration of $\mathrm{Na}^{+}$and subsequently $\mathrm{Ca}^{2+}$ influx. The sustained activation of calpain can lead to axonal degeneration, a hallmark of the pathophysiology of EAE [146]. Preservation of axonal integrity in EAE has been achieved by the administration of calpainspecific inhibitors such as CYLA [139]. This inhibitor can be synthesized by addition of cysteic acid (which can be actively transported into the brain through those mechanisms utilized by taurine to the leucyl-argininal of leupeptin), effectively crossing the blood-brain barrier [147]. Hassen and co-workers, [139], have recently shown that administration of intraperitoneal CYLA ( $2 \mathrm{mg}$ daily) resulted in reduced levels of $\beta \mathrm{APP}$-positive and $\mathrm{Na}_{\mathrm{v}}$ 1.6-positive axons (markers of axonal degeneration) in spinal cords of $\mathrm{MOG}_{35-55}$-induced EAE mice [139]. These data correlated with abrogated clinical scores in the CYLA-treated EAE mice and argue for the utilization of calpain inhibitors to limit axonal degeneration during neuroinflammatory CNS lesion formation, commonly characterized during MS pathogenesis.

\section{Calpain and CRMP-2}

There is now a more comprehensive argument for the provision of calpain inhibitors in MS and related neurological conditions. CRMP-2 has been identified as a common substrate for calpain-I during Wallerian degeneration in vitro, and calpain-mediated cleavage of CRMP-2 (Figure 3) may lead to its autophagic processing [148]. Calpain is reported to cleave CRMPs following ischemic brain injury in mice [149]. It cleaves CRMP-4 in primary rat cortical cultures as a result of either NMDA-induced excitotoxic insult or $\mathrm{H}_{2} \mathrm{O}_{2}$ induced oxidative stress [150]. Zhang and colleagues [151], have demonstrated calpain-mediated proteolysis of CRMP-1, -2 and -4 following neurotoxin treatment of primary cortical neurons and also following traumatic brain injury in the rat [151]. Hou and colleagues [152], have also found that calpain cleaves CRMP-3 following excitotoxic insult in vitro and cerebral ischemia in vivo. Interestingly, these investigators have shown that the cleaved product of CRMP-3, translocates to the nucleus and induces not only axonal retraction but also neuronal death [152]. This group has subsequently studied the expression patterns of all isoforms of CRMP (CRMP-1 to 5) and the proteolytic activity of calpain on CRMPs in ischemic brain injury, discovering that all CRMPs were highly expressed in apoptotic neurons [149]. Furthermore, synaptosomal CRMPs were found to be more susceptible to calpain cleavage than cytosolic CRMPs [149]. The physiological significance of this finding is unclear. However, it is possible that upon cleavage, synaptosomal CRMPs in particular, play a significant role in neuronal death with tantalizing implications to grey matter pathology in MS and clinical progression [153].

\section{Conclusion}

Permanent neurological deficits in MS are governed by CNS axonal degeneration of major fiber tracts but the molecular mechanisms, which contribute to this damage, are poorly understood. The major contributors to axonal damage and loss may include: (1) axoplasm energy depletion caused by mitochondrial injury elicited through a hypoxic environment of sustained ROS and RNS, generated through activated microglia; (2) increased expression of $\mathrm{Na}_{\mathrm{v}} 1.6$ and the $\mathrm{Na}^{+} / \mathrm{Ca}^{2+}$ exchanger, which mediate cytotoxic levels of intra-axonal $\mathrm{Ca}^{2+}$ to compensate $\mathrm{Na}^{+}$ influx; (3) through the dysregulation of axonal transport machinery which may include abnormal modifications to the microtubule-associated proteins such as CRMP-2, thereby culminating in catastrophic damage of the axonal cytoskeleton. As current immunomodulatory therapies 
are limited in their ability to reduce relapses and in many ways ineffective during SPMS or PPMS, future therapies must be designed to halt the progression of clinical severity. From pre-clinical and clinical data, it is becoming evident that axonal injury is directly related to clinical progression. Therefore, ameliorating axonal damage during MS can limit the severity of disease to enhance the quality of life for MS sufferers. However, the mechanisms of potential therapy targeting axonal degeneration must be clearly defined with the potential effects upon nonneuronal cells, documented to ensure disease stage specificity without contraindications for MS patients.

\begin{abstract}
Abbreviations
MS: Multiple sclerosis; RNFL: Retinal nerve fiber layer; OCT: Optical coherence tomography; DTI: Diffusion tensor imaging; CNS: Central nervous system; NAA: N-acetyl aspartate; NF-L: Neurofilament light chain; NF-H: Neurofilament heavy chain; SPMS: Secondary progressive multiple sclerosis; PPMS: Primary progressive MS; CRMP-2: Collapsin mediator protein-2; RRMS: Relapsingremiting multiple sclerosis; MRI: Magnetic resonance imaging: Gd: Gadolinium; EAE: Experimental autoimmune encephalomyelitis; mfVEP: Multifocal visual evoked potential; MRS: Magnetic resonance spectroscopy; NAA/Cr: NAA/Creatine; NAWM: Normal appearing white matter; ROS: Reactive oxygen species; RNS: Reactive nitrogen species; HDAC: Histone deacetylase; SIRT: Sirtuin; PGC-1a: Peroxisome proliferator activated receptor co-activator 1-a; BDNF: Brain-derived growth factor; ASIC1: Acid-sensing ion channel-1; Th1: Type 1 helper T cells; Th17: Type 17 helper T cells; IFN- - : Interferon-gamma; TNF: Tumor necrosis factor; BAPP: Amyloid precursor protein; GSK-3ß: glycogen synthase kinase $3 \beta$.
\end{abstract}

\section{Competing interest}

The authors declare that they have no competing interest.

\section{Authors' contributions}

$J Y L, K T$ and SP all wrote major sections of the manuscript. SP conceived the review and its structure. JYL constructed the Figures. SP edited the manuscript. All authors read and approved the final manuscript.

\section{Acknowledgments}

JYL supported by Multiple Sclerosis Research Australia Postgraduate Scholarship and Trish Multiple Sclerosis Research Foundation; KT supported by a Multiple Sclerosis Research Australia Student Vacation Scholarship; SP supported by National Multiple Sclerosis Society Project Grant \#RG4398A1/1.

\section{Author details}

${ }^{1}$ Department of Medicine, Central Clinical School, Monash University, Prahran, Victoria 3004, Australia. ${ }^{2}$ Melbourne Medical School, Faculty of Medicine, Dentistry and Health Sciences, University of Melbourne, Parkville, Victoria 3010, Australia.

Received: 5 August 2014 Accepted: 6 August 2014

Published: 27 August 2014

\section{References}

1. Ascherio A, Marrie RA (2012) Vitamin D in MS: a vitamin for 4 seasons. Neurology 79(3):208-210

2. Dutta R, Trapp BD (2011) Mechanisms of neuronal dysfunction and degeneration in multiple sclerosis. Prog Neurobiol 93(1):1-12

3. Calabresi PA (2004) Diagnosis and management of multiple sclerosis. Am Fam Physician 70(10):1935-1944

4. Polman CH, Reingold SC, Banwell B, Clanet M, Cohen JA, Filippi M, Fujihara K, Havrdova E, Hutchinson M, Kappos L, Lublin FD, Montalban X, O'Connor P, Sandberg-Wollheim M, Thompson AJ, Waubant E, Weinshenker B, Wolinsky JS (2011) Diagnostic criteria for multiple sclerosis: 2010 revisions to the McDonald criteria. Ann Neurol 69(2):292-302

5. Hauser SL, Oksenberg JR (2006) The neurobiology of multiple sclerosis: genes, inflammation, and neurodegeneration. Neuron 52(1):61-76
6. DeBoy CA, Zhang J, Dike S, Shats I, Jones M, Reich DS, Mori S, Nguyen T, Rothstein B, Miller RH, Griffin JT, Kerr DA, Calabresi PA (2007) High resolution diffusion tensor imaging of axonal damage in focal inflammatory and demyelinating lesions in rat spinal cord. Brain 130(Pt 8):2199-2210

7. Sbardella E, Tona F, Petsas N, Pantano P (2013) DTI Measurements in Multiple Sclerosis: Evaluation of Brain Damage and Clinical Implications. Mult Scler Int 2013:671730

8. Pierpaoli C, Jezzard P, Basser PJ, Barnett A, Di Chiro G (1996) Diffusion tensor MR imaging of the human brain. Radiology 201(3):637-648

9. Filippi M, lannucci G, Cercignani M, Assunta Rocca M, Pratesi A, Comi G (2000) A quantitative study of water diffusion in multiple sclerosis lesions and normal-appearing white matter using echo-planar imaging. Arch Neurol 57(7):1017-1021

10. Horsfield MA, Larsson HB, Jones DK, Gass A (1998) Diffusion magnetic resonance imaging in multiple sclerosis. J Neurol Neurosurg Psychiatry 64(Suppl 1):S80-S84

11. Filippi M (2001) Magnetic resonance imaging findings predicting subsequent disease course in patients at presentation with clinically isolated syndromes suggestive of multiple sclerosis. Neurol Sci 22(Suppl 2):S49-S51

12. Preziosa P, Rocca MA, Mesaros S, Pagani E, Stosic-Opincal T, Kacar K, Absinta M, Caputo D, Drulovic J, Comi G, Filippi M (2011) Intrinsic damage to the major white matter tracts in patients with different clinical phenotypes of multiple sclerosis: a voxelwise diffusion-tensor MR study. Radiology 260(2):541-550

13. Fink F, Klein J, Lanz M, Mitrovics T, Lentschig M, Hahn HK, Hildebrandt H (2010) Comparison of diffusion tensor-based tractography and quantified brain atrophy for analyzing demyelination and axonal loss in MS. J Neuroimaging 20(4):334-344

14. Griffin CM, Chard DT, Ciccarelli O, Kapoor B, Barker GJ, Thompson Al, Miller DH (2001) Diffusion tensor imaging in early relapsing-remitting multiple sclerosis. Mult Scler 7(5):290-297

15. Benedetti B, Rocca MA, Rovaris M, Caputo D, Zaffaroni M, Capra R, Bertolotto A, Martinelli V, Comi G, Filippi M (2010) A diffusion tensor MRI study of cervical cord damage in benign and secondary progressive multiple sclerosis patients. J Neurol Neurosurg Psychiatry 81(1):26-30

16. Liu Y, Duan Y, He Y, Yu C, Wang J, Huang J, Ye J, Parizel PM, Li K, Shu N (2012) Whole brain white matter changes revealed by multiple diffusion metrics in multiple sclerosis: a TBSS study. Eur J Radiol 81(10):2826-2832

17. Giorgio A, De Stefano N (2010) Cognition in multiple sclerosis: relevance of lesions, brain atrophy and proton MR spectroscopy. Neurol Sci 31(Suppl 2): S245-S248

18. Onu M, Roceanu A, Sboto-Frankenstein U, Bendic R, Tarta E, Preoteasa F, Bajenaru O (2012) Diffusion abnormality maps in demyelinating disease: correlations with clinical scores. Eur J Radiol 81(3):e386-e391

19. Ciccarelli O, Wheeler-Kingshott CA, McLean MA, Cercignani M, Wimpey K, Miller DH, Thompson AJ (2007) Spinal cord spectroscopy and diffusionbased tractography to assess acute disability in multiple sclerosis. Brain 130(Pt 8):2220-2231

20. Reich DS, Smith SA, Zackowski KM, Gordon-Lipkin EM, Jones CK, Farrell JA, Mori S, van Zijl PC, Calabresi PA (2007) Multiparametric magnetic resonance imaging analysis of the corticospinal tract in multiple sclerosis. Neuroimage 38(2):271-279

21. van der Walt A, Kolbe SC, Wang YE, Klistorner A, Shuey N, Ahmadi G, Paine M, Marriott M, Mitchell P, Egan GF, Butzkueven H, Kilpatrick TJ (2013) Optic nerve diffusion tensor imaging after acute optic neuritis predicts axonal and visual outcomes. PLoS One 8(12):e83825

22. Moll NM, Rietsch AM, Thomas S, Ransohoff AJ, Lee JC, Fox R, Chang A, Ransohoff RM, Fisher E (2011) Multiple sclerosis normal-appearing white matter: pathology-imaging correlations. Ann Neurol 70(5):764-773

23. Kallenbach K, Frederiksen J (2007) Optical coherence tomography in optic neuritis and multiple sclerosis: a review. Eur J Neurol 14(8):841-849

24. Klistorner A, Arvind H, Nguyen T, Garrick R, Paine M, Graham S, O'Day J, Grigg J, Billson F, Yiannikas C (2008) Axonal loss and myelin in early ON loss in postacute optic neuritis. Ann Neurol 64(3):325-331

25. Klistorner A, Sriram P, Vootakuru N, Wang C, Barnett MH, Garrick R, Parratt J, Levin N, Raz N, Van der Walt A, Masters L, Graham SL, Yiannikas C (2014) Axonal loss of retinal neurons in multiple sclerosis associated with optic radiation lesions. Neurology 82(24):2165-2172

26. Tewarie P, Balk L, Costello F, Green A, Martin R, Schippling S, Petzold A (2012) The OSCAR-IB consensus criteria for retinal OCT quality assessment. PLoS One 7(4):e34823

27. Schippling S, Balk L, Costello F, Albrecht P, Balcer L, Calabresi P, Frederiksen J, Frohman E, Green A, Klistorner A, Outteryck O, Paul F, Plant G, Traber G, 
Vermersch P, Villoslada P, Wolf S, Petzold A (2014) Quality control for retinal OCT in multiple sclerosis: validation of the OSCAR-IB criteria. Mult Scler, doi:10.1177/1352458514538110

28. Teunissen CE, Dijkstra C, Polman C (2005) Biological markers in CSF and blood for axonal degeneration in multiple sclerosis. Lancet Neurol 4(1):32-41

29. Filippi M, Bozzali M, Rovaris M, Gonen O, Kesavadas C, Ghezzi A, Martinelli V, Grossman Rl, Scotti G, Comi G, Falini A (2003) Evidence for widespread axonal damage at the earliest clinical stage of multiple sclerosis. Brain 126(Pt 2):433-437

30. Gonen O, Moriarty DM, Li BS, Babb JS, He J, Listerud J, Jacobs D, Markowitz CE, Grossman RI (2002) Relapsing-remitting multiple sclerosis and wholebrain $\mathrm{N}$-acetylaspartate measurement: evidence for different clinical cohorts initial observations. Radiology 225(1):261-268

31. Rovaris M, Gambini A, Gallo A, Falini A, Ghezzi A, Benedetti B, Sormani MP, Martinelli V, Comi G, Filippi M (2005) Axonal injury in early multiple sclerosis is irreversible and independent of the short-term disease evolution. Neurology 65(10):1626-1630

32. De Stefano N, Narayanan S, Francis SJ, Smith S, Mortilla M, Tartaglia MC, Bartolozzi ML, Guidi L, Federico A, Arnold DL (2002) Diffuse axonal and tissue injury in patients with multiple sclerosis with low cerebral lesion load and no disability. Arch Neurol 59(10):1565-1571

33. Fu L, Matthews PM, De Stefano N, Worsley KJ, Narayanan S, Francis GS, Antel JP, Wolfson C, Arnold DL (1998) Imaging axonal damage of normalappearing white matter in multiple sclerosis. Brain 121(Pt 1):103-113

34. Ruiz-Pena JL, Pinero P, Sellers G, Argente J, Casado A, Foronda J, Ucles A, Izquierdo G (2004) Magnetic resonance spectroscopy of normal appearing white matter in early relapsing-remitting multiple sclerosis: correlations between disability and spectroscopy. BMC Neurol 4:8

35. Srinivasan R, Sailasuta N, Hurd R, Nelson S, Pelletier D (2005) Evidence of elevated glutamate in multiple sclerosis using magnetic resonance spectroscopy at 3 T. Brain 128(Pt 5):1016-1025

36. Simone IL, Tortorella C, Federico F, Liguori M, Lucivero V, Giannini P, Carrara D, Bellacosa A, Livrea P (2001) Axonal damage in multiple sclerosis plaques: a combined magnetic resonance imaging and $1 \mathrm{H}$-magnetic resonance spectroscopy study. J Neurol Sci 182(2):143-150

37. Pascual AM, Martinez-Bisbal MC, Bosca I, Valero C, Coret F, MartinezGranados B, Marti-Bonmati L, Mir A, Celda B, Casanova B (2007) Axonal loss is progressive and partly dissociated from lesion load in early multiple sclerosis. Neurology 69(1):63-67

38. Oh J, Pelletier D, Nelson SJ (2004) Corpus callosum axonal injury in multiple sclerosis measured by proton magnetic resonance spectroscopic imaging. Arch Neurol 61(7):1081-1086

39. Sarchielli P, Presciutti O, Pelliccioli GP, Tarducci R, Gobbi G, Chiarini P, Alberti A, Vicinanza F, Gallai V (1999) Absolute quantification of brain metabolites by proton magnetic resonance spectroscopy in normal-appearing white matter of multiple sclerosis patients. Brain 122(Pt 3):513-52

40. Cader S, Johansen-Berg H, Wylezinska M, Palace J, Behrens TE, Smith S, Matthews PM (2007) Discordant white matter $\mathrm{N}$-acetylasparate and diffusion MRI measures suggest that chronic metabolic dysfunction contributes to axonal pathology in multiple sclerosis. Neuroimage 36(1):19-27

41. Blamire AM, Cader S, Lee M, Palace J, Matthews PM (2007) Axonal damage in the spinal cord of multiple sclerosis patients detected by magnetic resonance spectroscopy. Magn Reson Med 58(5):880-885

42. Parry A, Corkill R, Blamire AM, Palace J, Narayanan S, Arnold D, Styles P Matthews PM (2003) Beta-Interferon treatment does not always slow the progression of axonal injury in multiple sclerosis. J Neurol 250(2):171-178

43. Tiberio M, Chard DT, Altmann DR, Davies G, Griffin CM, McLean MA, Rashid W, Sastre-Garriga J, Thompson AJ, Miller DH (2006) Metabolite changes in early relapsing-remitting multiple sclerosis. A two year follow-up study. J Neurol 253(2):224-230

44. Zaaraoui W, Rico A, Audoin B, Reuter F, Malikova I, Soulier E, Viout P, Le Fur Y, Confort-Gouny S, Cozzone PJ, Pelletier J, Ranjeva JP (2010) Unfolding the long-term pathophysiological processes following an acute inflammatory demyelinating lesion of multiple sclerosis. Magn Reson Imaging 28(4):477-486

45. Bates TE, Strangward M, Keelan J, Davey GP, Munro PM, Clark JB (1996) Inhibition of $\mathrm{N}$-acetylaspartate production: implications for $1 \mathrm{H}$ MRS studies in vivo. Neuroreport 7(8):1397-1400

46. Narayana PA, Wolinsky JS, Rao SB, He R, Mehta M, Group PRTM (2004) Multicentre proton magnetic resonance spectroscopy imaging of primary progressive multiple sclerosis. Mult Scler 10(Suppl 1):S73-S78
47. Sarchielli P, Presciutti O, Tarducci R, Gobbi G, Alberti A, Pelliccioli GP, Chiarini P, Gallai V (2002) Localized (1)H magnetic resonance spectroscopy in mainly cortical gray matter of patients with multiple sclerosis. J Neurol 249(7):902-910

48. Sastre-Garriga J, Ingle GT, Chard DT, Ramio-Torrenta L, McLean MA, Miller DH, Thompson AJ (2005) Metabolite changes in normal-appearing gray and white matter are linked with disability in early primary progressive multiple sclerosis. Arch Neurol 62(4):569-573

49. Adalsteinsson E, Langer-Gould A, Homer RJ, Rao A, Sullivan EV, Lima CA Pfefferbaum A, Atlas SW (2003) Gray matter N-acetyl aspartate deficits in secondary progressive but not relapsing-remitting multiple sclerosis. AJNR Am J Neuroradiol 24(10):1941-1945

50. Gadea M, Martinez-Bisbal MC, Marti-Bonmati L, Espert R, Casanova B, Coret F, Celda B (2004) Spectroscopic axonal damage of the right locus coeruleus relates to selective attention impairment in early stage relapsing-remitting multiple sclerosis. Brain 127(Pt 1):89-98

51. Christodoulou C, Krupp LB, Liang Z, Huang W, Melville P, Roque C, Scherl WF, Morgan T, MacAllister WS, Li L, Tudorica LA, Li X, Roche P, Peyster R (2003) Cognitive performance and MR markers of cerebral injury in cognitively impaired MS patients. Neurology 60(11):1793-1798

52. Khan O, Shen Y, Bao F, Caon C, Tselis A, Latif Z, Zak I (2008) Long-term study of brain $1 \mathrm{H}-\mathrm{MRS}$ study in multiple sclerosis: effect of glatiramer acetate therapy on axonal metabolic function and feasibility of long-term H-MRS monitoring in multiple sclerosis. J Neuroimaging 18(3):314-319

53. Wood ET, Ronen I, Techawiboonwong A, Jones CK, Barker PB, Calabresi P, Harrison D, Reich DS (2012) Investigating axonal damage in multiple sclerosis by diffusion tensor spectroscopy. J Neurosci 32(19):6665-6669

54. Marques IB, Matias F, Silva ED, Cunha L, Sousa L (2014) Risk of multiple sclerosis after optic neuritis in patients with normal baseline brain MRI. J Clin Neurosci 21(4):583-586

55. Evans RW, Armon C, Frohman EM, Goodin DS (2000) Assessment: prevention of post-lumbar puncture headaches: report of the therapeutics and technology assessment subcommittee of the american academy of neurology. Neurology 55(7):909-914

56. Teunissen CE, Khalil M (2012) Neurofilaments as biomarkers in multiple sclerosis. Mult Scler 18(5):552-556

57. Kuhle J, Plattner K, Bestwick JP, Lindberg RL, Ramagopalan SV, Norgren N, Nissim A, Malaspina A, Leppert D, Giovannoni G, Kappos L (2013) A comparative study of CSF neurofilament light and heavy chain protein in MS. Mult Scler 19(12):1597-1603

58. Khalil M, Enzinger C, Langkammer C, Ropele S, Mader A, Trentini A, Vane ML, Wallner-Blazek M, Bachmaier G, Archelos JJ, Koel-Simmelink MJ, Blankenstein MA, Fuchs S, Fazekas F, Teunissen CE (2013) CSF neurofilament and $\mathrm{N}$-acetylaspartate related brain changes in clinically isolated syndrome. Mult Scler 19(4):436-442

59. Madeddu R, Farace C, Tolu P, Solinas G, Asara Y, Sotgiu MA, Delogu LG, Prados JC, Sotgiu S, Montella A (2013) Cytoskeletal proteins in the cerebrospinal fluid as biomarker of multiple sclerosis. Neurol Sci 34(2):181-186

60. Malmestrom C, Haghighi S, Rosengren L, Andersen O, Lycke J (2003) Neurofilament light protein and glial fibrillary acidic protein as biological markers in MS. Neurology 61(12):1720-1725

61. Huizinga R, Heijmans N, Schubert P, Gschmeissner S, $t^{\prime}$ Hart BA, Herrmann H, Amor S (2007) Immunization with neurofilament light protein induces spastic paresis and axonal degeneration in Biozzi ABH mice. J Neuropathol Exp Neurol 66(4):295-304

62. Huizinga R, Gerritsen W, Heijmans N, Amor S (2008) Axonal loss and gray matter pathology as a direct result of autoimmunity to neurofilaments. Neurobiol Dis 32(3):461-470

63. Kuhle J, Leppert D, Petzold A, Regeniter A, Schindler C, Mehling M, Anthony DC, Kappos L, Lindberg RL (2011) Neurofilament heavy chain in CSF correlates with relapses and disability in multiple sclerosis. Neurology 76(14):1206-1213

64. Gunnarsson M, Malmestrom C, Axelsson M, Sundstrom P, Dahle C, Vrethem M, Olsson T, Piehl F, Norgren N, Rosengren L, Svenningsson A, Lycke J (2011) Axonal damage in relapsing multiple sclerosis is markedly reduced by natalizumab. Ann Neurol 69(1):83-89

65. Axelsson M, Malmestrom C, Gunnarsson M, Zetterberg H, Sundstrom P, Lycke J, Svenningsson A (2014) Immunosuppressive therapy reduces axonal damage in progressive multiple sclerosis. Mult Scler 20(1):43-50

66. Kuhle J, Malmestrom C, Axelsson M, Plattner K, Yaldizli O, Derfuss T, Giovannoni G, Kappos L, Lycke J (2013) Neurofilament light and heavy subunits compared as therapeutic biomarkers in multiple sclerosis. Acta Neurol Scand 128(6):e33-e36 
67. Gnanapavan S, Grant D, Morant S, Furby J, Hayton T, Teunissen CE, Leoni V, Marta M, Brenner R, Palace J, Miller DH, Kapoor R, Giovannoni G (2013) Biomarker report from the phase II lamotrigine trial in secondary progressive MS - neurofilament as a surrogate of disease progression. PLoS One 8(8):e70019

68. Kiryu-Seo S, Ohno N, Kidd GJ, Komuro H, Trapp BD (2010) Demyelination increases axonal stationary mitochondrial size and the speed of axonal mitochondrial transport. J Neurosci 30(19):6658-6666

69. Friese MA, Schattling B, Fugger $L$ (2014) Mechanisms of neurodegeneration and axonal dysfunction in multiple sclerosis. Nat Rev Neurol 10(4):225-238

70. Witte ME, Mahad DJ, Lassmann H, van Horssen J (2014) Mitochondrial dysfunction contributes to neurodegeneration in multiple sclerosis. Trends Mol Med 20(3):179-187

71. Dutta R, McDonough J, Yin X, Peterson J, Chang A, Torres T, Gudz T, Macklin WB, Lewis DA, Fox RJ, Rudick R, Mirnics K, Trapp BD (2006) Mitochondrial dysfunction as a cause of axonal degeneration in multiple sclerosis patients. Ann Neurol 59(3):478-489

72. Campbell GR, Ziabreva I, Reeve AK, Krishnan KI, Reynolds R, Howell O, Lassmann H, Turnbull DM, Mahad DJ (2011) Mitochondrial DNA deletions and neurodegeneration in multiple sclerosis. Ann Neurol 69(3):481-492

73. Mahad DJ, Ziabreva I, Campbell G, Lax N, White K, Hanson PS, Lassmann H, Turnbull DM (2009) Mitochondrial changes within axons in multiple sclerosis. Brain 132(Pt 5):1161-1174

74. van Horssen J, Witte ME, Ciccarelli O (2012) The role of mitochondria in axonal degeneration and tissue repair in MS. Mult Scler 18(8):1058-1067

75. Zambonin JL, Zhao C, Ohno N, Campbell GR, Engeham S, Ziabreva I, Schwarz N, Lee SE, Frischer JM, Turnbull DM, Trapp BD, Lassmann H, Franklin RJ, Mahad DJ (2011) Increased mitochondrial content in remyelinated axons: implications for multiple sclerosis. Brain 134(Pt 7):1901-1913

76. Faraco G, Cavone L, Chiarugi A (2011) The therapeutic potential of HDAC inhibitors in the treatment of multiple sclerosis. Mol Med 17(5-6):442-447

77. Camelo S, Iglesias AH, Hwang D, Due B, Ryu H, Smith K, Gray SG, Imitola J, Duran G, Assaf B, Langley B, Khoury SJ, Stephanopoulos G, De Girolami U, Ratan RR, Ferrante RJ, Dangond F (2005) Transcriptional therapy with the histone deacetylase inhibitor trichostatin A ameliorates experimental autoimmune encephalomyelitis. J Neuroimmunol 164(1-2):10-21

78. Kim JY, Shen S, Dietz K, He Y, Howell O, Reynolds R, Casaccia P (2010) HDAC1 nuclear export induced by pathological conditions is essential for the onset of axonal damage. Nat Neurosci 13(2):180-189

79. Shen S, Sandoval J, Swiss VA, Li J, Dupree J, Franklin RJ, Casaccia-Bonnefil P (2008) Age-dependent epigenetic control of differentiation inhibitors is critical for remyelination efficiency. Nat Neurosci 11(9):1024-1034

80. Shindler KS, Ventura E, Rex TS, Elliott P, Rostami A (2007) SIRT1 activation confers neuroprotection in experimental optic neuritis. Invest Ophthalmol Vis Sci 48(8):3602-3609

81. Shindler KS, Ventura E, Dutt M, Elliott P, Fitzgerald DC, Rostami A (2010) Oral resveratrol reduces neuronal damage in a model of multiple sclerosis. J Neuroophthalmol 30(4):328-339

82. Khan RS, Fonseca-Kelly Z, Callinan C, Zuo L, Sachdeva MM, Shindler KS (2012) SIRT1 activating compounds reduce oxidative stress and prevent cell death in neuronal cells. Front Cell Neurosci 6:63

83. Nimmagadda VK, Bever CT, Vattikunta NR, Talat S, Ahmad V, Nagalla NK Trisler D, Judge SI, Royal W 3rd, Chandrasekaran K, Russell JW, Makar TK (2013) Overexpression of SIRT1 protein in neurons protects against experimental autoimmune encephalomyelitis through activation of multiple SIRT1 targets. J Immunol 190(9):4595-4607

84. Rafalski VA, Ho PP, Brett JO, Ucar D, Dugas JC, Pollina EA, Chow LM, Ibrahim A, Baker SJ, Barres BA, Steinman L, Brunet A (2013) Expansion of oligodendrocyte progenitor cells following SIRT1 inactivation in the adult brain. Nat Cell Biol 15(6):614-624

85. Pennisi G, Cornelius C, Cavallaro MM, Salinaro AT, Cambria MT, Pennisi M, Bella R, Milone P, Ventimiglia B, Migliore MR, Di Renzo L, De Lorenzo A, Calabrese V (2011) Redox regulation of cellular stress response in multiple sclerosis. Biochem Pharmacol 82(10):1490-1499

86. Waxman SG (2008) Mechanisms of disease: sodium channels and neuroprotection in multiple sclerosis-current status. Nat Clin Pract Neurol 4(3):159-169

87. Moll C, Mourre C, Lazdunski M, Ulrich J (1991) Increase of sodium channels in demyelinated lesions of multiple sclerosis. Brain Res 556(2):311-316

88. Kapoor R, Li YG, Smith KJ (1997) Slow sodium-dependent potential oscillations contribute to ectopic firing in mammalian demyelinated axons. Brain 120(Pt 4):647-652
89. Craner MJ, Newcombe J, Black JA, Hartle C, Cuzner ML, Waxman SG (2004) Molecular changes in neurons in multiple sclerosis: altered axonal expression of Nav1.2 and Nav1.6 sodium channels and Na+/Ca2+ exchanger. Proc Natl Acad Sci U S A 101(21):8168-8173

90. Rush AM, Dib-Hajj SD, Waxman SG (2005) Electrophysiological properties of two axonal sodium channels, Nav1.2 and Nav1.6, expressed in mouse spinal sensory neurones. J Physiol 564(Pt 3):803-815

91. Black JA, Newcombe J, Trapp BD, Waxman SG (2007) Sodium channel expression within chronic multiple sclerosis plaques. J Neuropathol Exp Neurol 66(9):828-837

92. Black JA, Liu S, Hains BC, Saab CY, Waxman SG (2006) Long-term protection of central axons with phenytoin in monophasic and chronic-relapsing EAE. Brain 129(Pt 12):3196-3208

93. Persson AK, Kim I, Zhao P, Estacion M, Black JA, Waxman SG (2013) Sodium channels contribute to degeneration of dorsal root ganglion neurites induced by mitochondrial dysfunction in an in vitro model of axonal injury J Neurosci 33(49):19250-19261

94. Bechtold DA, Yue X, Evans RM, Davies M, Gregson NA, Smith KJ (2005) Axonal protection in experimental autoimmune neuritis by the sodium channel blocking agent flecainide. Brain 128(Pt 1):18-28

95. Craner MJ, Damarjian TG, Liu S, Hains BC, Lo AC, Black JA, Newcombe J, Cuzner ML, Waxman SG (2005) Sodium channels contribute to microglia/ macrophage activation and function in EAE and MS. Glia 49(2):220-229

96. Black JA, Liu S, Carrithers M, Carrithers LM, Waxman SG (2007) Exacerbation of experimental autoimmune encephalomyelitis after withdrawal of phenytoin and carbamazepine. Ann Neurol 62(1):21-33

97. Brand-Schieber E, Werner P (2004) Calcium channel blockers ameliorate disease in a mouse model of multiple sclerosis. Exp Neurol 189(1):5-9

98. Kapoor R, Furby J, Hayton T, Smith KJ, Altmann DR, Brenner R, Chataway J, Hughes RA, Miller DH (2010) Lamotrigine for neuroprotection in secondary progressive multiple sclerosis: a randomised, double-blind, placebocontrolled, parallel-group trial. Lancet Neurol 9(7):681-688

99. Friese MA, Craner MJ, Etzensperger R, Vergo S, Wemmie JA, Welsh MJ, Vincent A, Fugger $L$ (2007) Acid-sensing ion channel-1 contributes to axonal degeneration in autoimmune inflammation of the central nervous system. Nat Med 13(12):1483-1489

100. Vergo S, Craner MJ, Etzensperger R, Attfield K, Friese MA, Newcombe J, Esiri M, Fugger $L$ (2011) Acid-sensing ion channel 1 is involved in both axonal injury and demyelination in multiple sclerosis and its animal model. Brain 134(Pt 2):571-584

101. Arun T, Tomassini V, Sbardella E, de Ruiter MB, Matthews L, Leite Ml, Gelineau-Morel R, Cavey A, Vergo S, Craner M, Fugger L, Rovira A, Jenkinson M, Palace J (2013) Targeting ASIC1 in primary progressive multiple sclerosis: evidence of neuroprotection with amiloride. Brain 136(Pt 1):106-115

102. Al-Izki S, Pryce G, Hankey DJ, Lidster K, von Kutzleben SM, Browne L, Clutterbuck L, Posada C, Edith Chan AW, Amor S, Perkins V, Gerritsen WH, Ummenthum K, Peferoen-Baert R, van der Valk P, Montoya A, Joel SP, Garthwaite J, Giovannoni G, Selwood DL, Baker D (2014) Lesional-targeting of neuroprotection to the inflammatory penumbra in experimental multiple sclerosis. Brain 137(Pt 1):92-108

103. Browne L, Lidster K, Al-Izki S, Clutterbuck L, Posada C, Chan AE, Riddall D, Garthwaite J, Baker D, Selwood DL (2014) Imidazol-1-ylethylindazole voltage gated sodium $(\mathrm{Na}$ ) channel ligands are neuroprotective during optic neuritis in a mouse model of multiple sclerosis. J Med Chem 57(7):2942-2952

104. Pomeroy IM, Jordan EK, Frank JA, Matthews PM, Esiri MM (2010) Focal and diffuse cortical degenerative changes in a marmoset model of multiple sclerosis. Mult Scler 16(5):537-548

105. Gray E, Rice C, Nightingale H, Ginty M, Hares K, Kemp K, Cohen N, Love S, Scolding N, Wilkins A (2013) Accumulation of cortical hyperphosphorylated neurofilaments as a marker of neurodegeneration in multiple sclerosis. Mult Scler 19(2):153-161

106. Papadopoulos D, Dukes S, Patel R, Nicholas R, Vora A, Reynolds R (2009) Substantial archaeocortical atrophy and neuronal loss in multiple sclerosis. Brain Pathol 19(2):238-253

107. Wegner C, Esiri MM, Chance SA, Palace J, Matthews PM (2006) Neocortical neuronal, synaptic, and glial loss in multiple sclerosis. Neurology 67(6):960-967

108. Dutta R, Chang A, Doud MK, Kidd GJ, Ribaudo MV, Young EA, Fox RJ, Staugaitis SM, Trapp BD (2011) Demyelination causes synaptic alterations in hippocampi from multiple sclerosis patients. Ann Neurol 69(3):445-454 
109. Hoffmann K, Lindner M, Groticke I, Stangel M, Loscher W (2008) Epileptic seizures and hippocampal damage after cuprizone-induced demyelination in C57BL/6 mice. Exp Neurol 210(2):308-321

110. Ziehn MO, Avedisian AA, Tiwari-Woodruff S, Voskuhl RR (2010) Hippocampal CA1 atrophy and synaptic loss during experimental autoimmune encephalomyelitis, EAE. Lab Invest 90(5):774-786

111. Kondo M, Takei Y, Hirokawa N (2012) Motor protein KIF1A is essential for hippocampal synaptogenesis and learning enhancement in an enriched environment. Neuron 73(4):743-757

112. Dutta R, Chomyk AM, Chang A, Ribaudo MV, Deckard SA, Doud MK, Edberg DD, Bai B, Li M, Baranzini SE, Fox RJ, Staugaitis SM, Macklin WB, Trapp BD (2013) Hippocampal demyelination and memory dysfunction are associated with increased levels of the neuronal microRNA miR-124 and reduced AMPA receptors. Ann Neurol 73(5):637-645

113. Derfuss T, Parikh K, Velhin S, Braun M, Mathey E, Krumbholz M, Kumpfel T, Moldenhauer A, Rader C, Sonderegger P, Pollmann W, Tiefenthaller C, Bauer J, Lassmann H, Wekerle H, Karagogeos D, Hohlfeld R, Linington C, Meinl E (2009) Contactin-2/TAG-1-directed autoimmunity is identified in multiple sclerosis patients and mediates gray matter pathology in animals. Proc Natl Acad Sci U S A 106(20):8302-8307

114. Choi SR, Howell OW, Carassiti D, Magliozzi R, Gveric D, Muraro PA, Nicholas R, Roncaroli F, Reynolds R (2012) Meningeal inflammation plays a role in the pathology of primary progressive multiple sclerosis. Brain 135(Pt 10):2925-2937

115. Howell OW, Reeves CA, Nicholas R, Carassiti D, Radotra B, Gentleman SM, Serafini B, Aloisi F, Roncaroli F, Magliozzi R, Reynolds R (2011) Meningeal inflammation is widespread and linked to cortical pathology in multiple sclerosis. Brain 134(Pt 9):2755-2771

116. Walker CA, Huttner AJ, O'Connor KC (2011) Cortical injury in multiple sclerosis; the role of the immune system. BMC Neurol 11:152

117. Lovato L, Willis SN, Rodig SJ, Caron T, Almendinger SE, Howell OW, Reynolds R, O'Connor KC, Hafler DA (2011) Related B cell clones populate the meninges and parenchyma of patients with multiple sclerosis. Brain 134(Pt 2):534-541

118. Magliozzi R, Howell OW, Reeves C, Roncaroli F, Nicholas R, Serafini B, Aloisi F, Reynolds R (2010) A Gradient of neuronal loss and meningeal inflammation in multiple sclerosis. Ann Neurol 68(4):477-493

119. Gardner C, Magliozzi R, Durrenberger PF, Howell OW, Rundle J, Reynolds R (2013) Cortical grey matter demyelination can be induced by elevated pro-inflammatory cytokines in the subarachnoid space of MOG-immunized rats. Brain 136(Pt 12):3596-3608

120. Coleman M (2005) Axon degeneration mechanisms: commonality amid diversity. Nat Rev Neurosci 6:889-898

121. Millecamps S, Julien JP (2013) Axonal transport deficits and neurodegenerative diseases. Nat Rev Neurosci 14(3):161-176

122. Ferguson B, Matyszak MK, Esiri MM, Perry VH (1997) Axonal damage in acute multiple sclerosis lesions. Brain 120(Pt 3):393-399

123. Hamajima N, Matsuda K, Sakata S, Tamaki N, Sasaki M, Nonaka M (1996) A novel gene family defined by human dihydropyrimidinase and three related proteins with differential tissue distribution. Gene 180(1-2):157-163

124. Quinn CC, Chen E, Kinjo TG, Kelly G, Bell AW, Elliott RC, McPherson PS, Hockfield S (2003) TUC-4b, a novel TUC family variant, regulates neurite outgrowth and associates with vesicles in the growth cone. J Neurosci 23(7):2815-2823

125. Fukata $Y$, Itoh TJ, Kimura T, Menager $C$, Nishimura T, Shiromizu T, Watanabe $\mathrm{H}$, Inagaki N, Iwamatsu A, Hotani H, Kaibuchi K (2002) CRMP-2 binds to tubulin heterodimers to promote microtubule assembly. Nat Cell Biol 4(8):583-591

126. Cole AR, Causeret F, Yadirgi G, Hastie CJ, McLauchlan H, McManus EJ, Hernandez F, Eickholt BJ, Nikolic M, Sutherland C (2006) Distinct priming kinases contribute to differential regulation of collapsin response mediator proteins by glycogen synthase kinase-3 in vivo. J Biol Chem 281(24):16591-16598

127. Uchida Y, Ohshima T, Sasaki Y, Suzuki H, Yanai S, Yamashita N, Nakamura F, Takei K, Ihara Y, Mikoshiba K, Kolattukudy P, Honnorat J, Goshima Y (2005) Semaphorin3A signalling is mediated via sequential Cdk5 and GSK3beta phosphorylation of CRMP2: implication of common phosphorylating mechanism underlying axon guidance and Alzheimer's disease. Genes Cells 10(2):165-179

128. Cole AR, Knebel A, Morrice NA, Robertson LA, Irving AJ, Connolly CN, Sutherland C (2004) GSK-3 phosphorylation of the Alzheimer epitope within collapsin response mediator proteins regulates axon elongation in primary neurons. J Biol Chem 279(48):50176-50180
129. Yoshimura T, Kawano Y, Arimura N, Kawabata S, Kikuchi A, Kaibuchi K (2005) GSK-3beta regulates phosphorylation of CRMP-2 and neuronal polarity. Cell 120(1):137-149

130. Arimura N, Menager C, Kawano Y, Yoshimura T, Kawabata S, Hattori A, Fukata Y, Amano M, Goshima Y, Inagaki M, Morone N, Usukura J, Kaibuchi K (2005) Phosphorylation by Rho kinase regulates CRMP-2 activity in growth cones. Mol Cell Biol 25(22):9973-9984

131. Arimura N, Inagaki N, Chihara K, Menager C, Nakamura N, Amano M, Iwamatsu A, Goshima Y, Kaibuchi K (2000) Phosphorylation of collapsin response mediator protein-2 by Rho-kinase. Evidence for two separate signaling pathways for growth cone collapse. J Biol Chem 275(31):23973-23980

132. Kawano Y, Yoshimura T, Tsuboi D, Kawabata S, Kaneko-Kawano T, Shirataki $\mathrm{H}$, Takenawa T, Kaibuchi K (2005) CRMP-2 is involved in kinesin-1-dependent transport of the Sra-1/WAVE1 complex and axon formation. Mol Cell Biol 25 (22):9920-9935

133. Williamson R, van Aalten L, Mann DM, Platt B, Plattner F, Bedford L, Mayer J, Howlett D, Usardi A, Sutherland C, Cole AR (2011) CRMP2 hyperphosphorylation is characteristic of Alzheimer's disease and not a feature common to other neurodegenerative diseases. J Alzheimers Dis 27(3):615-625

134. Petratos S, Li QX, George AJ, Hou X, Kerr ML, Unabia SE, Hatzinisiriou I, Maksel D, Aguilar MI, Small DH (2008) The beta-amyloid protein of Alzheimer's disease increases neuronal CRMP-2 phosphorylation by a Rho-GTP mechanism. Brain 131(Pt 1):90-108

135. Petratos S, Ozturk E, Azari MF, Kenny R, Lee JY, Magee KA, Harvey AR, McDonald C, Taghian K, Moussa L, Mun Aui P, Siatskas C, Litwak S, Fehlings MG, Strittmatter SM, Bernard CC (2012) Limiting multiple sclerosis related axonopathy by blocking Nogo receptor and CRMP-2 phosphorylation. Brain 135(Pt 6):1794-1818

136. Schaecher KE, Shields DC, Banik NL (2001) Mechanism of myelin breakdown in experimental demyelination: a putative role for calpain. Neurochem Res 26(6):731-737

137. Schaecher K, Rocchini A, Dinkins J, Matzelle DD, Banik NL (2002) Calpain expression and infiltration of activated T cells in experimental allergic encephalomyelitis over time: increased calpain activity begins with onset of disease. J Neuroimmunol 129(1-2):1-9

138. Shields DC, Tyor WR, Deibler GE, Hogan EL, Banik NL (1998) Increased calpain expression in activated glial and inflammatory cells in experimental allergic encephalomyelitis. Proc Natl Acad Sci U S A 95(10):5768-5772

139. Hassen GW, Feliberti J, Kesner L, Stracher A, Mokhtarian F (2008) Prevention of axonal injury using calpain inhibitor in chronic progressive experimental autoimmune encephalomyelitis. Brain Res 1236:206-215

140. Trager N, Smith A, Wallace IV G, Azuma M, Inoue J, Beeson C, Haque A, Banik NL (2014) Effects of a novel orally administered calpain inhibitor SNJ1945 on immunomodulation and neurodegeneration in a murine model of multiple sclerosis. J Neurochem, doi:10.1111/jnc.12659

141. Vosler PS, Brennan CS, Chen J (2008) Calpain-mediated signaling mechanisms in neuronal injury and neurodegeneration. Mol Neurobiol 38(1):78-100

142. Siman R, Baudry M, Lynch G (1984) Brain fodrin: substrate for calpain I, an endogenous calcium-activated protease. Proc Natl Acad Sci U S A 81 (11):3572-3576

143. Johnson GV, Jope RS, Binder LI (1989) Proteolysis of tau by calpain. Biochem Biophys Res Commun 163(3):1505-1511

144. Taghian K, Lee JY, Petratos S (2012) Phosphorylation and cleavage of the family of collapsin response mediator proteins may play a central role in neurodegeneration after CNS trauma. J Neurotrauma 29(9):1728-1735

145. Chan SL, Mattson MP (1999) Caspase and calpain substrates: roles in synaptic plasticity and cell death. J Neurosci Res 58(1):167-190

146. Das A, Guyton MK, Butler JT, Ray SK, Banik NL (2008) Activation of calpain and caspase pathways in demyelination and neurodegeneration in animal model of multiple sclerosis. CNS Neurol Disord Drug Targets 7(3):313-320

147. Koyama Y, Baba A, Iwata H (1990) Characteristics of Cl(-)-dependent L-[35S] cysteic acid transport into rat brain synaptic membrane vesicles. Neurochem Res 15(12):1153-1158

148. Touma E, Kato S, Fukui K, Koike T (2007) Calpain-mediated cleavage of collapsin response mediator protein(CRMP)-2 during neurite degeneration in mice. Eur J Neurosci 26(12):3368-3381

149. Jiang SX, Kappler J, Zurakowski B, Desbois A, Aylsworth A, Hou ST (2007) Calpain cleavage of collapsin response mediator proteins in ischemic mouse brain. Eur J Neurosci 26(4):801-809

150. Kowara R, Chen Q, Milliken M, Chakravarthy B (2005) Calpain-mediated truncation of dihydropyrimidinase-like 3 protein (DPYSL3) in response to NMDA and H2O2 toxicity. J Neurochem 95(2):466-474 
151. Zhang Z, Ottens AK, Sadasivan S, Kobeissy FH, Fang T, Hayes RL, Wang KK (2007) Calpain-mediated collapsin response mediator protein-1, -2 , and -4 proteolysis after neurotoxic and traumatic brain injury. J Neurotrauma 24(3):460-472

152. Hou ST, Jiang SX, Desbois A, Huang D, Kelly J, Tessier L, Karchewski L, Kappler J (2006) Calpain-cleaved collapsin response mediator protein-3 induces neuronal death after glutamate toxicity and cerebral ischemia. J Neurosci 26(8):2241-2249

153. Lee MS, Kwon YT, Li M, Peng J, Friedlander RM, Tsai LH (2000) Neurotoxicity induces cleavage of p35 to p25 by calpain. Nature 405(6784):360-364

doi:10.1186/s40478-014-0097-7

Cite this article as: Lee et al:: Axonal degeneration in multiple sclerosis: can we predict and prevent permanent disability? Acta Neuropathologica Communications 2014 2:97.

\section{Submit your next manuscript to BioMed Central and take full advantage of:}

- Convenient online submission

- Thorough peer review

- No space constraints or color figure charges

- Immediate publication on acceptance

- Inclusion in PubMed, CAS, Scopus and Google Scholar

- Research which is freely available for redistribution 